\title{
X Kuşağında Sportmenlik Yönelimi
}

\author{
DOI: $10.26466 /$ opus.524867
}

\section{Hüseyin Gümüș}

* Dr. Öğretim Üyesi, Mersin Üniversitesi, Beden Eğitimi ve Spor Yüksekokulu, Mersin / Türkiye E-Posta: huseyinn.gumuss@gmail.com

ORCID:0000-0003-1870-3073

\section{Öz}

Sportmenlik konusunda yapılan araştırmaların agırlıklı olarak genç kuşak üzerine yoğunlaştı̆̆ı görülmektedir. Bu araştırmada $x$ kuşă̆g olarak adlandırılan orta yaş grubunun sportmenlik yönelimlerinin incelenmesi amaçlanmıştır. Araştırmaya Afyonkarahisarda bulunan 1965-1980 yılları arasında doğan 128'i kadın, 269'u erkek olmak üzere toplamda 397 birey gönüllü olarak katılmıştır. Araştırmada veri toplama aracı olarak Çok Boyutlu Sportmenlik Yönelimi Ölçeği (ÇBSYÖ) kullanılmıştır. ÇBSYÖ Vallerand ve arkadaşları (1997) tarafindan geliştirilen, Türkçe geçerlik ve güvenirlik çalışmaş SezenBalçıkanlı (2010) tarafindan yapılan, 20 madde ve 4 alt boyuttan oluşan 5'li Likert türünde bir ölçektir. Verilerin analizinde betimsel istatistiklerin (yüzde, frekans vs.) yanı sıra açıklayıcı faktör analizi (AFA), değişken sayısına bağlı olarak iki grup için Bağımsız Örneklem T Testi, ikiden fazla grup için Tek Yönlü Varyans Analizi kullanılmıştır. Yapılan varyans analizi sonucunda elde edilen farkların hangi gruplardan kaynaklandığının tespiti için çoklu karşılaştırma testlerinden Tukey testi kullanılmıştır. X kuşağında en yüksek ortalamaların sosyal normlara uyum alt boyutunda olduğ u, onu sirasılyla kurallara ve yönetime saygı alt boyutu ve sporda sorumluluklara bağlllık alt boyutlarının izlediği, en düşük ortalamanın ise rakibe saygı alt boyutunda olduğ $u$ tespit edilmiştir. Sportmenlik yöneliminin spor kulübüne üye olma durumu ve eğitim seviyesine göre farklılaşmadığı görülürken, düzenli spor yapan bireylerin tüm alt boyutlarda düzenli spor yapmayan bireylere oranla daha olumlu cevaplar verdiği tespit edilmiştir. Son olarak erkek katılimcilarm "Kurallara ve yönetime saygi" alt boyutunda puan ortalamalarının kadın katılımcılara oranla daha yüksek olduğu görülmüştür.

Anahtar Kelimeler: Sportmenlik, $x$ kuşağı, fair play 


\title{
Sportspersonship Orientation in X Generation
}

\begin{abstract}
Previous studies have shown that recent academic studies about sportspersonship tended to focusing on the young generation. In this study, it was aimed to examine the sportspersonship orientations of the middle age group called X generation. 397 people who burned in 1965-1980 (128 women, 269 men) voluntarily participated in this study. In the research, Multidimensional Sportspersonship Orientation Scale (MSOS) was used as a data collection tool. MSOS was developed by Vallerand et al. (1997). The validity and reliability study to the Turkish language of MSOS was performed by Sezen-Balçıanl (2010). The scale consists of 20 items and 4 sub-dimensions. The scale is a 5-point Likert scale. For the analyses of the data; descriptive statistics, Independent Samples T-Test for two groups, and One Way ANOVA for more than two groups were used. Tukey Post-hoc test was used to determine the source of difference in multiple comparisons. The highest average in the $X$ generation are in the sub-dimension of "respect for social convention", and other high averages are in the sub-dimensions of "respect for rules and officials" and "respect for one's full commitment". The lowest average is "respect for opponents". It was decided that sportspersonship did was not different according to the status of being a member of a sports club or level of their education. People who doing exercise regularly gave more reply positively in all sub-dimensions than people do not. Finally, the mean score of male participants in sub-dimension of "respect for rules and officials" higher than female participants.
\end{abstract}

Keywords: Sportspersonship, $x$ generation, fair play 


\section{Giriş}

Spor kavramı dünya genelinde milyonlarca insanın hayatında önemli bir noktada yer almaktadır. Gerek aktif olarak spor yapmış bireyler, gerek ateşli taraftarlar gerekse sadece pasif izleyici boyutundakiler olsun herkesin bir şekilde hayatının bir döneminde spora dokunmuş olduğunu söylemek yanlış olmayacaktır. Sporun böylesine büyük bir kitleye bir şekilde dokunmuş olmasının sebebi hiç şüphesiz farklı kültürlerden, farklı etnik kökenlerden gelen insanları hatta farklı dilleri konuşan ve farklı dünya görüşüne sahip insanları bile aynı bütünleştirici ve kapsayıcı şemsiye altında toplayabiliyor olmasıdır. Farklılıkları birleştiren bu olgu bir yandan dünyanın dört bir köşesinden insanları bir gol ile coştururken diğer taraftan hiç tanımadığınız birine sarılıp takımınız için gözyaşı dökmenize de yol açabilmektedir. Bu duygu yoğunluğunu çok daha ileri düzeyde yaşayan bireyler fanatiklik ve fanatizm kavramlarının ön plana çıkmasını sağlamaktadır. Bir adanmışlık ya da bağlanma biçimi olarak nitelendirilen (Yıldız ve Açak, 2018) fanatizm, bünyesinde hem olumlu hem de olumsuz ifadeleri barındırmaktadır. Örneğin, bir sporcuyu veya takımı ölesiye sevmek sosyal bir onay olarak ifade edilirken, içerisinde şiddet ve saldırganlığı da barındıran davranış sosyal olarak kabul edilemez olarak ifade edilmektedir (Berument ve diğ., 2009). Sosyolojide, psikolojide ve spor bilimlerinde birçok araştırmaya konu olan fanatizm kavramı (Chung ve diğ., 2018; Taşmektepligil ve diğ., 2017; Gümüş ve diğ., 2016; Yücel ve diğ., 2015; Çetin, 2015; Taşmektepligil ve diğ., 2015; Yıldıran, 2005) fair play olgusuyla zıt anlamlı olarak kullanılmaktadır. En yalın anlamıyla adil ve dürüst oyunu vurgulayan fair play davranışı sağlıklı toplumu oluşturan sağlıklı ve ahlaklı bireylerden beklenmektedir. 20. yy boyunca, spordan ticari ve siyasi beklentilerin artması, ahlaki beklentileri ikinci plana iterek amatör ruhun profesyonellik karşısında değer kaybetmesine neden olmuştur. Sporda erdemsiz davranışlardaki artış, fair play anlayışının kazandırılmasının öncelikli olarak sistemli ve uzun vadeli bir eğitim sürecini zorunlu kıldığını ortaya koymuştur. Bunun sonucunda fair play kültürünün oluşturulmasına ilişkin çalışmalarda, hareket noktasının ilköğretim ve orta öğretim öğrencilerinin oluşturması gerektiği düşüncesi ağırlık kazanmaya başlamıştır (Yıldıran, 2005). Türkiye'de fair play alanında yapılan çalışmalar incelendiğinde, 
ağırlıklı olarak öğrenci gruplarına ya da genç bireylere odaklanıldığı görülmektedir (Güllü ve Şahin, 2018; Şebin ve diğ., 2007; Çalayır ve diğ., 2017; Kayışoğlu ve diğg., 2015; Güllü, 2018; Koç, 2017; Türkmen ve Varol, 2015; Balçıkanlı ve diğ., 2017). Fakat her ne kadar genç bir nüfusa sahip olsak da orta yaş üstü bireylerin de fair play kavramına yönelik görüşleri, tutum ve davranışları araştırılmaya değer bir konudur. $X$ kuşağı olarak adlandırılan bu yaş grubu 1965-1980 yılları arasında doğan bireyleri kapsamaktadır. Aynı kuşaktan gelen bireylerin, birbirlerine yakın yıllarda dünyaya geldikleri için, tutum ve davranışları, benzer olaylara verdikleri benzer tepkiler ile şekillenmektedir (Başol ve Çetinaydın, 2014). Ek olarak, aynı doğum yıllarını paylaşan bireyler birbirlerini aynı grubun üyesi olarak tanımlarken, diğerlerini farklı kuşağın mensubu olarak görmektedirler. Dolayısıyla, aynı jenerasyonun insanları diğer kuşaklara mensup bireylerden ayırt edilebilir. Aynı kuşaktan gelen bireyler için sadece paylaşılan yıllar değil, paylaşılan sosyal ve tarihsel olaylar da, kuşakların bir takım özelliklerini kalıcı olarak etkilemektedir (Sullivan ve diğ., 2009). Nesil, batın ya da jenerasyon kelimeleriyle de ifade edilebilen kuşak kavramı 25- 30 yıllık yaş kümelerini oluşturan bireyler öbeği olarak tanımlanmaktadır (TDK, 2019). Kuşakların tutum ve değerlerinin farklı olduğuna dair alg1 ve inanç, özellikle belirli bir grup araştırmacı, eğitimci, yönetim danışmanları ve grupları tarafından gündemde tutulmaktadır (Gürbüz, 2015). Kuşaklar sosyal etkileşimlerin bir sonucu olarak ortaya çıkmakta ve belirli olgulara ve olaylara yönelik ortak bir bilinç, fikir, dünya görüşü ve deneyim geliştirmektedirler (Glas, 2007). Bu görüşü destekler nitelikte bir araştırmada, savaş ve toplumsal açıdan bunalımlı dönemlerde yetişen kuşakların ekonomik belirlenimcilik, otoriteye saygılı olma, materyalizm ve rasyonalizm, gibi modern hayat tarızına dair bir takım değerleri öğrendikleri; sosyal ve ekonomik olarak refahın bulunduğu dönemlerde büyüyen kuşakların ise eşitlikçilik, farklılıklara karşı hoşgörü ve öz-paylaşım gibi postmodern değerleri öğrendikleri ileri sürülmektedir (Egri ve Ralston, 2004). Bireylerin ilerleyen yaşlarına rağmen, ilk yıllarda deneyimledikleri eylemlerin etkisiyle oluşturdukları baskın tutum ve davranışları ilerleyen süreçte de devam ettirdikleri tezi, farklı araştırmacılar tarafından savunulmaktadır (Lu ve Gürsoy, 2016; Smith ve Clurman, 1997; Wey Smola ve Sutton, 2002; Inglehart, 1997). 
Kuşak farklılıklarına yönelik yapılan bilimsel çalışmaların 4 farklı kuşak sinıflandırması üzerine yoğunlaştığı görülmektedir. Bu sınıflandırma:

- Bebek Patlaması Kuşağı (Baby Boomers; 1946 - 1964 arası doğanlar),

- X Kuşağı (1965 - 1980 arası doğanlar),

- Y kuşağı (1980 - 2000 arasında doğanlar),

- Z Kuşağı (2000 yılı ve sonrasında doğanlar) şeklindedir (Twenge ve diğ. 2010).

$\mathrm{Bu}$ araştırmada $\mathrm{x}$ kuşağ 1 üzerine yoğunlaşılacaktır. Araştırmanın amacl, $x$ kuşağının sportmenlik yönelimlerinin incelenmesidir.

\section{Yöntem}

Nicel araştırma yöntemlerinin uygulandığı bu çalışma, kesitsel tarama türünde, betimsel bir araştırmadır. Betimsel araştırmalar, genelde verilen bir durumu aydınlatmak, olaylar arasında olası ilişkileri ortaya çıarmak ve standartlar doğrultusunda değerlendirmeler yapmak için yürütülür. Betimsel araştırmalar; bir durumu olabildiğince tam ve dikkatli bir şekilde tanımlanmasını sağlayan çalışmalardır. Tarama modeli; bir konuya veya olaya ilişkin katılımcıların görüşlerinin ya da ilgi, beceri, yetenek, tutum vb. özelliklerinin belirlendiği genellikle büyük örneklem grupları üzerine yapılan araştırmalardır (Büyüköztürk ve diğ., 2014).

\section{Çalışma Grubu}

Araştırmanın evrenini Afyonkarahisar'da yaşayan 1965-1980 yılları arasında doğan bireyler oluşturmaktadır. Araştırmaya bu evrenden amaçsal örnekleme yöntemlerinden ölçüt örnekleme metodu ile seçilen 128 kadın $(44.22 \pm 1.12)$ ve $269(49.26 \pm 1.54)$ erkek olmak üzere toplam 397 birey dâhil edilmiştir.

\section{Veri Toplama Formu}

Araştırmada veri toplama formu olarak araştırmacı tarafından geliştirilen demografik bilgi formunun yanı sıra Çok Boyutlu Sportmenlik Yönelimi Ölçeği (ÇBSYÖ) kullanılmıştır. ÇBSYÖ, Vallerand ve arkadaşları (1997) tarafından geliştirilen, Türkçe geçerlik ve güvenirlik çalışması Sezen- 
Balçıkanlı (2010) tarafından yapılan, 20 madde ve 4 alt boyuttan oluşan 5'li Likert türünde bir ölçektir. ÇBSYÖ'nün bu çalışma için Cronbach Alpha değerleri ise; Faktör 1 (Sosyal Normlara Uyum) 0,87; Faktör 2 (Kurallara ve Yönetime Sayg1) 0,81; Faktör 3 (Sporda Sorumluluklara Bağlılık) 0,88; Faktör 4 (Rakibe Sayg1) 0,79'dir. Değerler, yüksek derecede güvenilir düzeydedir.

\section{Verilerin Toplanması}

Araştırmanın verileri 2017 yılında Afyonkarahisar il merkezinde toplanmıştır. Veri toplama formları uygulanmadan önce, uygulamanın sportmenlik yönelimi ile ilgili olduğu, formlara isim yazılmaması gerektiği ve verilen cevapların sadece bu bilimsel araştırma kapsamında kullanılacağ belirtilmiştir. Her bir sorunun cevaplandırılmasının önemi vurgulanarak kişilerin gönüllü olarak araştırmaya katılmaları sağlanmıştır. Formun tamamlanması ortalama 7 dakika zaman almıştır.

\section{Verilerin Çözümlenmesi}

Verilerin analizinde betimsel istatistiklerin (yüzde, frekans vs.) yanı sıra açımlayıcı faktör analizi (AFA), değişken sayısına bağlı olarak iki grup için Bağımsız Örneklem T Testi (Independent Samples T Test), ikiden fazla grup için Tek Yönlü Varyans Analizi (One Way ANOVA) kullanılmıştır. Yapılan varyans analizi sonucunda elde edilen farkların hangi gruplardan kaynaklandığının tespiti için çoklu karşılaştırma testlerinden Tukey testi kullanılmıştır.

\section{Bulgular}

Tablo 1. X kuşağının sportmenlik yönelimi ölçeğine ilişkin alt boyut puan ortalamalart

\begin{tabular}{lcc}
\hline Çok Boyutlu Sportmenlik Yönelimi & $\overline{\boldsymbol{x}}$ & ss \\
\hline Sosyal normlara uyum & 3,77 & 1,28 \\
Kurallara ve yönetime saygı & 3,49 &, 99 \\
Sporda sorumluluklara bağlılık & 3,48 & 1,09 \\
Rakibe sayg1 & 2,81 & 1,14 \\
\hline
\end{tabular}


Araştırmaya katılan bireylerin çok boyutlu sportmenlik yönelimi ölçeğine verdikleri cevaplar incelendiğinde en yüksek ortalamaların sosyal normlara uyum alt boyutunda olduğu, onu sirasiyla kurallara ve yönetime saygı alt boyutu ve sporda sorumluluklara bağlılık alt boyutu izlemektedir. Çok boyutlu sportmenlik ölçeğinin alt boyutlarına ilişkin yapılan analizde en düşük ortalamanın rakibe saygı alt boyutunda olduğu görülmektedir.

Tablo 2. Sosyal normlara uyum alt boyutunun cinsiyet, spor kulübü üyesi olma ve düzenli egzersiz yapma durumlarna göre t-testi sonuçlar

\begin{tabular}{|c|c|c|c|c|c|c|}
\hline ÇBSYÖ & Değişken & $\mathbf{n}$ & $\bar{x}$ & ss & $\mathbf{t}$ & p \\
\hline \multirow{6}{*}{ 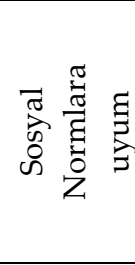 } & Erkek & 269 & 3,75 & 1,23 & \multirow{2}{*}{$-3,373$} & \multirow{2}{*}{,709 } \\
\hline & Kadın & 128 & 3,80 & 1,39 & & \\
\hline & Spor kulübü üyesi & 112 & 3,82 & 1,32 & \multirow{2}{*}{,467 } & \multirow{2}{*}{,641 } \\
\hline & Spor kulübü üyesi değil & 285 & 3,75 & 1,27 & & \\
\hline & Düzenli egzersiz yapan & 167 & 3,94 & 1,31 & \multirow{2}{*}{2,281} & \multirow{2}{*}{, $023^{*}$} \\
\hline & Düzenli egz. yapmayan & 230 & 3,64 & 1,25 & & \\
\hline
\end{tabular}

${ }^{*} \mathrm{p}<0.05$

Çok boyutlu sportmenlik yönelimi ölçeğinin sosyal normlarla uyum alt boyutuna ilişkin puan ortalamaları incelendiğinde düzenli egzersiz yapma durumunun anlamlı farklılığa yok açtığı söylenebilir. Düzenli egzersiz yapan bireylerin sosyal normlara uyum alt boyutunda düzenli egzersiz yapmayan bireylere oranla daha yüksek ortalamalara sahip olduğu görülmektedir.

Tablo 3. Kurallara ve yönetime saygı alt boyutunun cinsiyet, spor kulübü üyesi olma ve dïzenli egzersiz yapma durumlarnna göre $t$-testi sonuçları

\begin{tabular}{|c|c|c|c|c|c|c|}
\hline ÇBSYÖ & Değişken & $\mathbf{n}$ & $\bar{x}$ & ss & $\mathbf{t}$ & p \\
\hline \multirow{6}{*}{ 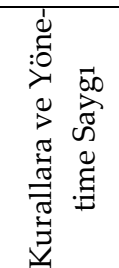 } & Kadın & 269 & 3,41 & 1,01 & \multirow{2}{*}{$-2,332$} & \multirow{2}{*}{, $020^{*}$} \\
\hline & Erkek & 128 & 3,66 & ,93 & & \\
\hline & Sk üyesi & 112 & 3,59 & 98 & \multirow{2}{*}{1,320} & \multirow{2}{*}{ 188 } \\
\hline & Sk üyesi değil & 285 & 3,44 & ,99 & & \\
\hline & Düzenli egz. yapan & 167 & 3,60 & 91 & \multirow{2}{*}{2,067} & \multirow{2}{*}{,039* } \\
\hline & Düzenli egz. yapmayan & 230 & 3,40 & 1,03 & & \\
\hline
\end{tabular}

${ }^{*} \mathrm{p}<0.05$ 
Kurallara ve yönetime saygı alt boyunda bireylerin cinsiyeti ve düzenli spor yapma durumlarının anlamlı farklılık yarattığ görülmektedir. Bu bilgiler 1şığında erkeklerin kadınlara oranla ve düzenli egzersiz yapanların yapmayanlara oranla daha olumlu puanlara sahip olduğu söylenebilir.

Tablo 4. Sporda sorumluluklara bağlllk alt boyutunun cinsiyet, spor kulübü üyesi olma ve dïzenli egzersiz yapma durumlarna göre $t$-testi sonuçlarn

\begin{tabular}{|c|c|c|c|c|c|c|}
\hline ÇBSYÖ & Değişken & $\mathbf{n}$ & $\bar{x}$ & ss & $t$ & p \\
\hline \multirow{6}{*}{ 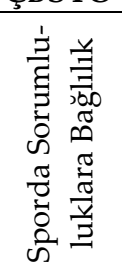 } & Kadın & 269 & 3,55 & 1,09 & \multirow{2}{*}{1,678} & \multirow{2}{*}{,094 } \\
\hline & Erkek & 128 & 3,35 & 1,10 & & \\
\hline & Sk üyesi & 112 & 3,41 & 1,20 & \multirow{2}{*}{,777 } & \multirow{2}{*}{,438 } \\
\hline & Sk üyesi değil & 285 & 3,51 & 1,05 & & \\
\hline & Düzenli egz. yapan & 167 & 3,58 & 1,03 & \multirow{2}{*}{$-2,137$} & \multirow{2}{*}{, $033^{*}$} \\
\hline & Düzenli egz. yapmayan & 230 & 3,34 & 1,16 & & \\
\hline
\end{tabular}

Tablo 4 incelendiğinde düzenli egzersiz yapan bireylerin yapmayanlara oranla sporda sorumluluklara bağlllık alt boyutunda daha yüksek ortalamalara sahip oldukları söylenebilir. Diğer taraftan cinsiyet ve spor kulübü üyesi olma değişkenlerinin sporda sorumluluklara bağlllık alt boyutunda anlamlı farklılık yaratmadığı görülmektedir.

Tablo 5. Rakibe saygı alt boyutunun cinsiyet, spor kulübü üyesi olma ve düzenli egzersiz yapma durumlarına göre t-testi sonuçları

\begin{tabular}{|c|c|c|c|c|c|c|}
\hline ÇBSYÖ & Değişken & $\mathbf{n}$ & $\bar{x}$ & ss & $\mathbf{t}$ & $\mathrm{p}$ \\
\hline \multirow{6}{*}{ 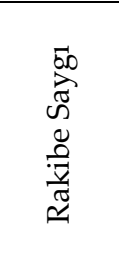 } & Kadın & 269 & 2,83 & 1,11 & \multirow{2}{*}{, 543} & \multirow[b]{2}{*}{,588 } \\
\hline & Erkek & 128 & 2,76 & 1,19 & & \\
\hline & Sk üyesi & 112 & 2,89 & 1,30 & \multirow{2}{*}{,962 } & \multirow{2}{*}{,337 } \\
\hline & Sk üyesi değil & 285 & 2,78 & 1,07 & & \\
\hline & Düzenli egz. yapan & 167 & 2,87 & 1,05 & \multirow{2}{*}{$-1,231$} & \multirow{2}{*}{,219 } \\
\hline & Düzenli egz. yapmayan & 230 & 2,73 & 1,24 & & \\
\hline
\end{tabular}

En düşük puan ortalamalarına sahip olan rakibe saygı alt boyutu incelendiğinde, cinsiyet, spor kulübüne üye olma durumu ve düzenli egzersiz yapma değişkenlerinin anlamlı farklılık yaratmadığı görülmektedir. Dolayısıyla kadın ya da erkek olmanın spor kulübü üyesi olmanın ya 
da düzenli egzersiz yapıyor olmanın rakibe saygı alt boyutunda anlamlı farklılık yaratmadığı görülmektedir.

\section{Tartışma}

Sportmenlik kavramı üzerine yapılan araştırmaların genel olarak genç kuşak üzerine yoğunlaşmış olması orta yaş grubun sportmenlik konusundaki tutumlarının incelenmesini gerekli kılmaktadır. Kendini topluma zıt olarak gören, sert politik çıkışlar yapan, gerek giyim tarzıyla gerekse dinledikleri müziklerle farklı yaşayış biçimlerine sahip olan bir nesil olarak gören x kuşağı, kendi var oluşlarını saygın bir statüye sahip olma, para ve yüksek oranda sosyalleşme ile açıklamaya çalışmaktadırlar (Coupland, 1989). Kanaat duyguları yüksek ve toplumsal sorunlara karşı duyarlı olduğu iddia edilen x kuşağ1 (Bristow ve diğ., 2011; Oblinger, 2003), özgürlüklerine düşkün, sabırsız ve iş odaklı kuşak olarak da anılmaktadır (Toruntay, 2011). Farklı özellikleriyle ön plana çıkan x kuşağının fair play konusundaki görüş ve tutumları incelendiğinde en yüksek ortalamaların sosyal normlara uyum alt boyutunda olduğu görülmektedir. Daha çok risk alma ve geçerli ritüel ve gelenekler gibi otoriteleri önceki kuşaklara göre daha fazla sorgulama eğiliminde olmalarıyla bilinen (Zhank ve Bong, 2010) bir kuşağın, söz konusu sportmenlik davranışı olunca sosyal normlara uyuma ilişkin tutumları son derece ilgi çekicidir. Müsabakadan sonra tokalaşma, rakibin iyi performansını fark etme ve iyi bir kaybeden olma gibi sporda karşılaşılabilecek durumlar sporda sosyal normlara uyum ile ilgilidir (Vallerand ve diğ., 1997). Reisenwitz ve Iyer (2009) X kuşağının kendilerini geliştirmeye ve çalıştıkları organizasyonda kültürel ve küresel değerler olmasına önem verdiklerini belirtmişlerdir. $\mathrm{Bu}$ bağlamda, sportmenlik davranışının bu kuşak için sosyo-kültürel bir değer olarak algılandığı düşünülmektedir. Nitekim, Bristow ve arkadaşları (2011) X kuşağının önceki kuşaklara göre daha fazla sorumluluk üstlendiğini, buna bağlı olarak değer gelişimlerinin daha üst seviyede olduğunu bildirmişlerdir.

$X$ kuşağının çok boyutlu sportmenlik yönelimi ölçeğine verdikleri cevaplara ilişkin en düşük puan ortalamalarının "rakibe saygi" alt boyutunda olduğu görülmektedir. X kuşağında dikkat çeken en önemli özelliklerden birkaçı amaç odaklı olmaları (Barlett, 2005) şüpheci, 
mücadeleci ve rekabetçi kişilikleridir (Şenturan ve diğ. 2016). X kuşağının mücadeleci ve rekabetçi olmaları onların rakiplerine bakış açılarını da etkilemektedir. Yapılan çalışmalar rakibe bakış açısının sportmenlik davranışı ile yüksek ilişki içerisinde olduğunu göstermektedir (SezenBalçıkanlı ve Yıldıran, 2011; Chantal ve diğ., 2005). Rakibe bakış açısı, oyunun gidişatını etkileyen önemli bir unsurdur. Rakibi oyunun bir parçası gibi görmek, rakip olmazsa oyunun da olmayacağının farkında olmak sportmenlik davranışının sergilenmesi için bir ön koşul niteliğindedir. Olayın ahlaki boyutunun bu çerçeveden değerlendirilmesi $\mathrm{X}$ kuşağında gözlemlenen en büyük eksiklik olarak karşımıza çıkmaktadır. Şenbir (2004) x kuşağ 1 için “Değişen dünyanın dinamiklerinin acımasızca yüzlerine çarptığı, ekonomik sorunlarla yüz yüze gelmiş bir kuşak" ifadesi kullanırken kurumlara karşı güven eksikliğinin bu dönemde oluştuğunu belirtmiştir. Bu ve benzeri faktörlerin "rakibe saygi" alt boyutuna ilişkin düşük ortalamaların nedeni olduğu düşünülmektedir.

\section{Sonuç ve Öneriler}

Sonuç olarak, x kuşağının çok boyutlu sportmenlik yönelimi incelendiğinde en yüksek puan ortalamalarının "Sosyal normlara uyum" alt boyutunda oldu, en düşük ortalamaların ise "rakibe sayg1" alt boyutunda olduğu görülmektedir. X kuşağında çeşitli değişkenlerin sportmenlik davranışında bir farklılığa neden olup olmadığ incelendiğinde, düzenli egzersiz yapma durumunun "Sosyal normlara uyum", "Kurallara ve Yönetime Sayg1" ve "Sporda sorumluluklara bağl1lık" boyutlarında anlamlı farklılığa neden olduğu görülmüştür. Puan ortalamaları incelendiğinde, düzenli egzersiz yapan bireylerin tüm alt boyutlarda düzenli egzersiz yapmayan bireylere oranla daha yüksek puan ortalamalarına sahip olukları görülmektedir. Bu bulgu, bireylere sportmenlik, fair play, spor ahlakı gibi kavramların kazandırılmasında düzenli egzersiz yapmanın, bireylerin bir şekilde sürekli sporla münasebetlerinin olmasının ne kadar önemli olduğunu göstermektedir. $X$ kuşağında her hangi bir spor kulübüne üye olma durumunun, sportmenlik yöneliminde bir fark yaratmadığı tespit edilmiştir. Son olarak, erkek katılımcıların "Kurallara ve yönetime saygı" alt boyutunda puan ortalamalarının kadın katılımcılara oranla daha yüksek olduğu görülmüştür. Bu 
bulgudan hareketle $\mathrm{x}$ kuşağında sportmenelik davranışı kazandırmaya yönelik çalışmaların kadın ağırlıklı olarak yürütülmesi önerilebilir. Araştırma grubunun eğitim seviyesinin sportmenlik yönelimi altboyutlarında herhangi bir farklılık yaratmadığı görülmüştür. Sportmenlik yöneliminin $x$ kuşağında, eğitim seviyesine göre değişmediği söylenebilir. Farklı kuşaklar üzerine benzer bir uygulama yapılarak kuşaklar arası farklılıkların incelenmesi, sportmenlik davranışını etkileyebileceği düşünülen farklı sosyal ve psikolojik değişkenlerin de incelenmesi aynı konuda yapılacak benzer çalışmaları daha değerli kılacaktır. 


\title{
EXTENDED ABSTRACT
}

\section{Sportspersonship Orientation in X Generation}

\author{
Huseyin GÜMÜŞ
}

\begin{abstract}
Mersin University
The term sport occupies a significant place in lives of millions of people over the world. It is not wrong to say that everybody -whether or not they are those who do sports actively or those who are strong supporters or those who are only passive spectators- must have touched sport somehow in any part of their lives. The reason why sport is so popular for such a large mass of people is doubtlessly that sport is capable of bringing people of different cultures, ethnicities, languages and even world perspectives together like an integrating and inclusive umbrella. On the one hand, sport may cheer up people who are coming from different parts of the world through only a score on the other hand it may make you shed tears for your team by hugging someone you do not know at all. Yet, those who experience these emotions at an extreme level produce the term fanaticism. The term fanaticism -being a study topic of sociology, psychology and sport sciences in numerous researches (Chung et al., 2018; Taşmektepligil et al., 2017; Gümüş et al., 2016; Yücel et al., 2015; Çetin, 2015; Taşmektepligil et al., 2015; Yıldiran, 2005)- is referred as an antonym of fair play. In the simplest sense, fair play behavior -emphasizing a just and fair game- is expected from healthy and moral individuals who make up a healthy society. In the 20th century; increased commercial and political demand from sports pushed moral expectations into the background and caused amateurism to be devalued by professionalism. Rise in unmoral behaviors has made it compulsory to establish -primarily- a systemized and long term educational process in order to create fair play understanding. Consequently, studies on establishing fair play culture have concluded that the starting point should be students of primary schools and high schools (Yildıran, 2005). However, even if we have a young population, it is worth studying opinions, attitudes and behaviors of middle aged indi-
\end{abstract}


viduals about fair play, too. This age group, called as $\mathrm{X}$ generation, includes those born between 1965 and 1980. Since individuals of the same generation are born in similar years, their attitudes and behaviors are shaped by similar reactions given to similar events (Başol and Çetinaydın, 2014). Additionally, those sharing the same birth years define themselves as a member of the same group but see others as a member of a different generation. Therefore, those of the same generation can be distinguished from those of other generations. For individuals that belong to the same generation; not only years shared but also common social and historical events affect features of generations permanently, too (Sullivan et al., 2009). It is seen that scientific studies on generation differences have focused on classification of four generations. The classification is as follows:

- Baby Boomers born 1946 - 1964,

- X generation born 1965 - 1980,

- Y generation born $1980-2000$,

- Z generation born $\geq 2000$ (Twenge et al. 2010).

The current study will focus on $x$ generation. The purpose of the current study is to investigate orientation of sportspersonship of $x$ generation. The study, in which quantitative research methods were used, was a crosssectional and descriptive study. The population of the study was consisted of those who were born between 1965 and 1980 and lived in Afyonkarahisar Province. 397 individuals [128 female participants (44.22 \pm 1.12$)$ vs. 269 male participants $(49.26 \pm 1.54)]$ were recruited for the study from the population using criterion sampling, which is one of the purposive sampling methods. As data collection tools; Information Request Form designed by the researcher and Multidimensional Sportspersonship Orientation Scale (MSOS) were used.

MSOS is a five point Likert type scale with 20 items and 4 subscales and was designed by Vallerand et al. (1997) and its Turkish validity and reliability tests were performed by Sezen-Balçıkanlı (2010). MSOS Cronbach Alpha coefficients in the current study were 0.87 for Factor 1 (respect for social convention); 0.81 for Factor 2 (respect for rules and officials); 0.88 for Factor 3 (respect for one's full commitment) and 0.79 for Factor 4 (respect for opponents). These coefficients were highly reliable. To analyze the data; -in addition to the descriptive statistics (percentages, frequencies, etc.)- Explanatory Factor Analysis (EFA), Independent Samples T Test for 
two groups -depending on the number of the variables-, One Way ANOVA for more than two groups were employed. One of the multiple comparison tests, Tukey test was used in order to explore which group caused differences obtained as a result of the variance analyses done.

As a conclusion; when multidimensional sportspersonship orientation of $x$ generation was examined, it was identified that highest average score was obtained in "respect for social convention" while the lowest average score in "respect for opponents". When whether or not various variables caused differences in sportspersonship behaviors among $X$ generation was investigated; it was found that doing exercises regularly produced a significant difference in "respect for social convention", "respect for rules and officials" and "respect for one's full commitment". Considering average scores, it was seen that those doing exercises regularly demonstrated higher average scores in all subdimensions as compared to those not doing exercises regularly. This proved how important it was to make individuals do exercises regularly and be engaged always with sports somehow in order to achieve such moral behaviors as sportspersonship, fair play, sports morality. It was identified that being a member of any sports club did not create any difference in sportspersonship orientation among $X$ generation. Finally, it was found that average scores of "respect for rules and officials" of male participants were higher than female participants. According to this finding, it may be suggested that studies that will target at creating sportsmanship behavior among $\mathrm{x}$ generation should mainly be undertaken with female population. It was seen that educational status of the study group did not produce any difference in sportspersonship orientation behavior and it may be argued that sportspersonship orientation did not differ in terms of educational status among $x$ generation. To investigate generation differences by doing similar studies on different generations and to investigate different social and psychological variables that are thought to affect sportspersonship behaviors will make similar and relevant studies more valuable. 


\section{Kaynakça / References}

Balçıkanlı, G. S., Gülşen, K., ve Yıldıran, İ. (2017). Kadın futbolcularda sportmenlik yönelimi. Gazi Beden Ĕ̆itimi ve Spor Bilimleri Dergisi, 22(1-4), 1-9.

Bartlett, M. (2005). Generation X? So old school: The emphasis now is on the 'millennials'. Credit Union Journal, 19(8), 14.

Başol, O. ve Çetin Aydın, G. (2014). X ve Y Kuşağı: Çalışmanın anlamında bir değişme var mı?. Electronic Journal of Vocational Colleges, 4(4), 115.

Berument, M. H., Ceylan, N. B. ve Ogut-Eker, G. (2009). Soccer, stock returns and fanaticism: Evidence from Turkey. The social science journal, 46(3), 594-600.

Bristow, D., Amyx, D., Castleberry, S. B. ve Cochran, J. J. (2011). A crossgenerational comparison of motivational factors in a sales career among Gen-X and Gen-Y college students. Journal of Personal Selling $\mathcal{E}$ Sales Management, 31(1), 77-85.

Büyüköztürk, Ş., Çakmak, E. K., Akgün, Ö. E., Karadeniz, Ş. ve Demirel, F. (2014). Bilimsel araştırma yöntemleri. Ankara: Pagem Akademi.

Chantal, Y., Robin, P., Vernat, J. P. ve Bernache-Assollant, I. (2005). Motivation, sportspersonship, and athletic aggression: a mediational analysis. Psychology of Sport and Exercise, 6(2), 233-249.

Chung, E., Farrelly, F., Beverland, M. B. ve Karpen, I. O. (2018). Loyalty or liability: Resolving the consumer fanaticism paradox. Marketing Theory, 18(1), 3-30.

Coupland, D. (1989). The young and restless work force following the baby boom: Generation X. (http://joeclark.org/dossiers/GenerationX.pdf) Erişim Tarihi: 11.11.2018.

Çalayır, Ö., Yıldız, N., Yaldız, Ö. ve Çoknaz, H. (2017). Hokey müsabakalarına katılan sporcuların beden eğitimi dersi sportmenlik davranışlarının incelenmesi. İstanbul Üniversitesi Spor Bilimleri Dergisi, 7(2), 27-37.

Çetin, E. (2015). Çocuk ve gençlerin televizyonda maç izleme alışkanlıklarının spordaki şiddet eylemlerine etkileri. International Journal of Science Culture and Sport, 3(Special Issue 3), 828-844. 
Egri, C. P. ve Ralston, D. A. (2004). Generation cohorts and personal values: A comparison of China and the United States. Organization Science, 15(2), 210-220.

Glass, A. (2007). Understanding generational differences for competitive success, Industrial and Commercial Training, 39, 98-103.

Güllü, S. (2018). Sporcuların antrenör-sporcu ilişkisi ile sportmenlik yönelimleri üzerine bir araştırma. Spormetre Beden Eğitimi Ve Spor Bilimleri Dergisi, 16(4), 190-204.

Güllü, S. ve Şahin, S. (2018). Milli güreşçilerin sportmenlik yönelim düzeyleri üzerine bir araştırma. Electronic Turkish Studies, 13(18), 705- 718.

Gümüş, H., Saraçlı, S., Karakullukçu, Ö. F., Doğanay, G. ve Kurtipek, S. (2016). Ortaöğretim öğrencilerinde fair play kavramı. International Journal of Science Culture and Sport (IntJSCS), 4(2), 430-438. Doi: 10.14486/IntJSCS568

Gürbüz, S. (2015). Kuşak farklılıkları: Mit mi, gerçek mi. İş ve İnsan Dergisi, 2(1), 39-57.

Inglehart, R. (1997). Modernization and postmodernization: cultural, economic, and political change in 43 societies, Princeton, NJ: Princeton University Press.

Kayışoğlu, N. B., Altınkök, M., Temel, C. ve Yüksel, Y. (2015). Ortaokul öğrencilerinin beden eğitimi dersi sportmenlik davranışlarının incelenmesi: Karabük İli Örneği. International Journal of Social Sciences and Education Research, 1(3), 1045-1056.

Koç, Y. (2017). Beden eğitimi dersinde sportmenlik davranışı kazandırmaya yönelik uygulama önerisi: küçüklerin oyununda centilmenliğin yapılandırılması (KOCY). Erzincan Üniversitesi Eğitim Fakültesi Dergisi, 19(2), 212-227.

Lu, A. C. C. ve Gursoy, D. (2016). Impact of job burnout on satisfaction and turnover intention: Do generational differences matter?. Journal of Hospitality \& Tourism Research, 40(2), 210-235.

Oblinger, D. (2003). Boomers gen-xers millennials. EDUCAUSE review, 500(4), 37-47.

Reisenwitz, T. H. ve Iyer, R. (2009). Differences in generation X and Y: implications for the organization and marketers. Marketing Management Journal, 19(2), 91- 103. 
Senbir, H. (2004). Z Son İnsan mı?, İstanbul: Okuyan Us Yayınları.

Sezen-Balçıkanlı, G. (2010). Çok boyutlu sportmenlik yönelimi ölçeği'nin türkçe uyarlaması: geçerlik ve güvenirlik çalışması. Gazi Beden Eğitimi ve Spor Bilimleri Dergisi, 15(1), 1-10.

Sezen-Balçikanlı, G. ve Yıldıran, I. (2011). Profesyonel futbolcuların sportmenlik yönelimleri ve empatik eğilim düzeyleri. SPORMETRE Be den Ë̆itimi ve Spor Bilimleri Dergisi, 9(2), 49-56.

Smith, J. W. ve Clurman, A. (1997). Rocking the ages: the yankelovich report on generational marketing, New York: Harper Collins.

Sullivan, S.E., Forret, M.L., Carraher, S.M. ve Maiminero, L.A. (2009). Using the kaleidescope career model to examine generational differences in work attitudes. Fairfield University Digital Commons, 14(3), 284-302.

Şebin, K., Tozoğlu, E., Yılmaz, S., Demirel, N. ve Bostancı, Ö. (2007). Spor yapan üniversite öğrencilerinin fair play'e ilişkin görüşleri. Journal of Physical Education and Sport Sciences, 9(2), 1-14.

Şenturan, Ş., Köse, A., Dertli, E., Başak, S. ve Şentürk, N. (2016). X ve Y Kuşağı Yöneticilerinin İş Değerleri Algısı ve Farklılıkları Üzerine İnceleme. Business E Economics Research Journal, 7(3), 171-182.

Taşmektepligil, M. Y., Çankaya, S. ve Taner, T. (2015). Futbol taraftarı fanatiklik ölçeği. Spor ve Performans Araştırmaları Dergisi, 6(1), 4149.

Taşmektepligil, M. Y., Küçük, V., Karakuş, S. ve Kalkavan, A. (2017). Bireysel şiddet açısından spor medyasının etkileri. Marmara University Journal of Sport Science, 2(2), 30-42. DOI: 10.22396/sbd.2017.29

TDK büyük türkçe sözlük. http://www.tdk.gov.tr/index.php?option=com_bts\&arama=kelime\&guid=TDK.GTS.5c504d2cad0336.12275127. 11.11.2018 tarihinde erişildi.

Toruntay, H. (2011). Takım rolleri çalışması: X ve Y kuşağı üzerinde karşılaştırmalı bir araştırma. Yayınlanmamış Yüksek Lisans Tezi, İstanbul Üniversitesi, Sosyal Bilimler Enstitüsü, İstanbul.

Türkmen, M. ve Varol, S. (2015). Beden eğitimi ve spor dersinin ortaokul öğrencileri üzerinde sportmenlik davranışı oluşturma etkisinin belirlenmesi: (Bartın İl Örneği). Uluslararası Güncel Eğitim Araştırmaları Dergisi, 1(1), 42-64. 
Twenge, J.M., Campell, S.M., Hoffman B.J., Lance C.E. (2010). Generational differences in work value: Leisure and extrinsic value increasing, social and intrinsic value decreasing. Journal of Management, 36(5), 1117-1147.

Vallerand, R. J., Briere, N. M., Blanchard, C. ve Provencher, P. (1997). Development and validation of the multidimensional sportspersonship orientations scale. Journal of Sport \& Exercise Psychology, 19(2), 197-206.

Wey Smola, K. ve Sutton, C. D. (2002). Generational differences: Revisiting generational work values for the new millennium. Journal of Organizational Behavior: The International Journal of Industrial, Occupational and Organizational Psychology and Behavior, 23(4), 363-382.

Yıldıran İ. (2005). Fair play eğitiminde beden eğitiminin rolü. Gazi Beden Eğitimi ve Spor Bilimleri Dergisi, 10(1), 3-16.

Yıldız, H. ve Açak, M. (2018). Examination of football fanaticism levels of high school students. Journal of the Faculty of Education, 19(3), 738748.

Yücel, A. S., Atalay, A. ve Gürkan, A. (2015). Sporda şiddet ve saldırganlığ etkileyen unsurlar. Uluslararası Hakemli Psikiyatri ve Psikoloji Araştırmalarn Dergisi, 2(2), 68-90. Doi: 10.17360/UHPPD.201529603

Zhang, K. ve Bonk, C. J. (2010). Generational learners ve e-learning technologies. Handbook of research on practices and outcomes in e-learning: issues and trends. USA: IGI-Global, 76-92.

\section{Kaynakça Bilgisi / Citation Information}

Gümüş, H. (2019). X kuşağında sportmenlik yönelimi. OPUS-Uluslararası Toplum Araştırmaları Dergisi , 10(17), 738-755. DOI: 10.26466/ opus.524867 